\title{
Inhalt
}

Editorial 5

\section{SCHWERPUNKTTHEMA: POETIKEN DER INTERKULTURALITÄT}

Poetiken der Interkulturalität

Einführung in das Thema

Dieter HeIMböckEL/IULIA-Karin PATRUT 9

Unerhört anders oder "wenn nur der Geist neu ist"

Interkulturalität und Novelle

DIETER HEIMBÖCKEL

Musils 'Portugiesine liest Novalis

IULIA-KARIN PATRUT

Postkolonialismus und Umwelt

Race, Gender und Öl in Lion Feuchtwangers Drama

Die Petroleuminseln

FRANZISKA SCHÖSSLER

61

Komische Variation, burleske Transposition und karnevaleske Dekonstruktion

Modalitäten der poetischen Reflexion des gesellschaftlichen Umgangs

mit Differenz in The Bohemian Girl (1936)

MATTHIAS BAUER

\section{Eine Afrikanerin in Schlesien}

Gerhart Hauptmanns Kriminalnovelle Der Schuß im Park (1939)

MichAELA HOLDENRIED

89

Dunkle Schatten unter Rotlicht

Interkulturelle Kontexte bei Sa'adat Hasan Manto und Charles Baudelaire

SWATI ACHARYA. 103

(Anti-)Antisemitismus und Kapitalismuskritik

Erinnerungskulturelle und zeitkritische Konflikte

in R.W. Fassbinders Drama Der Müll, die Stadt und der Tod

ANDREA GEIER 
„Fäden, viele Fäden.“

Ungewisse Vermischungen in dem Roman Eine Glückliche Liebe von Hubert Fichte

MANFRED WEINBERG

Südsee-Projektionen in der deutschen Gegenwartsliteratur

Transnationale Imaginationen ferner Welten in ausgewählten Texten von Buch,

Capus und Kracht

DaVid Simo/Jean BerTRand MiguOUÉ

\section{AUS LITERATUR UND THEORIE}

Herkunft - Ähnlichkeit - Tod

Saša Stanišić' Herkunft und Sigmund Freuds Signorelli-Geschichte

DOMINIK ZINK 171

\section{FORUM}

Germanistik in Deutschland und in Italien während der Covid-19-Krise

Ein Gespräch

MARCELLA COSta/KAI BREMER 189

\section{REZENSIONEN}

Johannes Görbert/Nikolas Immer (Hg.): Ambulante Poesie.

Explorationen deutschsprachiger Reiselyrik seit dem 18. Jahrhundert

STEFAN HERMES

Alois Wierlacher: Hingabe und Vertragsstiftung. Lessings Emilia Galotti und Goethes Iphigenie auf Tauris als Dramen bibelkritischer bzw. rechtspolitischer Sicherung menschlichen Lebens und Zusammenlebens.

ANNE-ROSE MEYER

Enikő Dácz/Réka Jakabházi (Hg.): Literarische Rauminszenierungen in Zentraleuropa.

Kronstadt/Braşov/Brassó in der ersten Hälfte des 20. Jahrhunderts

KATALIN TELLER

\section{GESELLSCHAFT FÜR INTERKULTURELLE GERMANISTIK}

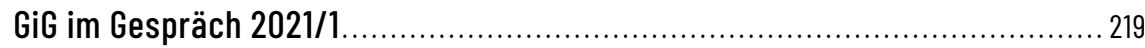

Autorinnen und Autoren ................................................................ 223

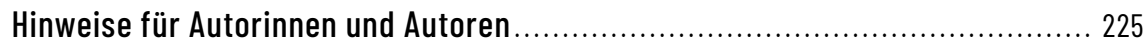

